\title{
Some aspects of semantic frames and meaning
}

\author{
Svetlana Yordanova Nedelcheva ${ }^{1}$, Mariana Todorova Krysteva $^{2}$ \\ 1 - Konstantin Preslavsky University of Shumen, Faculty of Humanities, 115, Universitetska St, 9700 Shumen, Bulgaria \\ 2 - Technical University of Varna, Department of Mathematics, Physics and Foreign Languages, 9010, 1 Studentska Street, Varna, Bulgaria \\ Corresponding author contact: $\underline{\text { s.nedelcheva@shu.bg }}$
}

\begin{abstract}
The paper offers a review of the linguistic literature dealing with the cognitive approaches to exploring language. It focuses on frame semantics as presenting a systematic description of language meaning and the role of frames in creating conceptual categories. The approaches discussed are applied to a corpus of technical texts and the examples are analysed in terms of the framework suggested.
\end{abstract}

Keywords: cognitive linguistics, semantic frames, image schemas, motion verbs

\section{Introduction}

In the last thirty years Cognitive linguistics is gaining grounds as a modern school of linguistic analysis. It emerged in the early 1970s because of discrepancies between the traditional approaches to language and the modern tendencies in the development of cognitive science, especially in studies related to human categorisation and Gestalt psychology. In the 1990s the research in this area spread rapidly and a great number of researchers started recognizing themselves as 'cognitive linguists'. According to the eminent cognitive linguist Ronald Langacker ([1991] 2002, p. Xv), this 'marked the birth of cognitive linguistics as a broadly grounded, self-conscious intellectual movement'.

Evans and Green (2006, p. 3) describe Cognitive linguistics as "an approach that has adopted a common set of guiding principles, assumptions and perspectives which have led to a diverse range of complementary, overlapping (and sometimes competing) theories". Its followers use these theories to build up models, which represent the systems behind language. Cognitive linguists argue against the traditional view that language is "pre-specified" in the sense that grammatical organisation is outlined in our minds, and semantic organization is governed by a pre-existing set of semantic primitives. Instead they suggest that linguistic organisation reflects embodied cognition, which is common to all human beings. Rather than interpreting language as deriving from a specialised set of innate cognitive universals, cognitive linguists see language as a reflection of embodied cognition, which serves to delimit what it is possible to experience, and therefore what it is possible to express in language.

There are various perspectives that linguists apply in exploring language. Some of them choose to focus on the systems within and between sound, meaning and grammar, or deal with more applied issues, such as the evolution of language, language acquisition and the problems associated with it, language changes over time, or the relationship between language, culture and society. For cognitive linguists, it is important to relate the systematicity exhibited by language directly to the processes in the mind, and in particular to conceptual structure and organisation.

To investigate that system they rely upon what language tells us about itself. They collect 'raw data' from the ordinary language, spoken every day by ordinary people. Linguists describe language, and based on its properties, formulate hypotheses, which can be tested in a number of ways. 


\section{Frames and scripts}

A semantic frame is defined as "a script-like conceptual structure that describes a particular type of situation, object, or event and the participants and props involved in it" (Ruppenhofer et al 2005:1). According to Goffman, "frames are basic cognitive structures which guide the perception and representation of reality". Fillmore defines the key term frame as "any system of concepts related in such a way that to understand any one of them you have to understand the whole structure in which it fits... a system of categories structured in accordance with some motivating context" $(2006: 371,381)$. The motivating context, in its turn, refers to "some body of understandings, some pattern of practices, or some history of social institutions, against which we find intelligible the creation of a particular category in the history of the language community" (2006: 381).

Frame is the central theoretical notion in Frame semantics, a term which refers to a wide variety of approaches to the systematic description of natural language meanings. These meanings have internal structure, which is determined relative to a background frame or a scene. This thesis can be illustrated by the following example proposed by Charles Fillmore (1977c):

(1) I spent three hours on land this afternoon.

(2) I spent three hours on the ground this afternoon.

The background scene for the first sentence is a sea voyage, while the second sentence refers to an interruption of an air travel. This illustrates Fillmore's use of the term frame as an idealization of a coherent perception, action, experience, memory, or object (Fillmore 1977c).

Similarly, in the following examples taken from the corpus of technical texts (except for (4a), the meaning and the conceptual categories constructed also rely on the particular frames which are evoked.

(3) a. Rollers...run on rails which are attached to the watertight bulkhead.

b. Engines which run on residual fuel are normally of $250 \mathrm{~mm}$ bore and upward.

c. System 3 has a GMDSS version of the telex terminal which runs on a dedicated computer.

d. Steam range lines run on the port and starboard sides of the ship...

(4) a. You may occasionally run across the street but it is dangerous.

b. You may occasionally run across a vacuum governor.

c. This equilibrium line ... runs across from a low speed line at low pressure ratio to a high speed line at high pressure ratio.

Thus sentences (3a) and (4a) refer to actual motion (requiring animate or inanimate agent and path), whereas the rest of the sentences exhibit other extended meanings that are metaphorically or metonymically motivated. Example (3b) is related to machinery operation/type of the fuel used; (3c) is associated with computer programme execution (it could be noted that in the two instances the agent is inanimate and does not perform actual motion, i.e. cannot be referred to as a trajectory, and the constructions do not feature the settings of SOURCE, GOAL and PATH). Sentences (3d) and (4c) do not express actual motion, but 'fictive motion' (different terms found in the literature suggest 'fictive motion' (Talmy, 2000), 'abstract motion' (Langacker, 1987), or 'subjective motion' (Matsumoto, 1996) and example (4b) denotes perception, with an obligatorily animate agent - 'perceiver'. In all the examples, however, the construction of the meaning is achieved through frame identification based on previous knowledge and experience.

There are at least two historical roots of Frame semantics; the first is Fillmore's case grammar (1977a) referring to the syntax and semantics of language, the second is Artificial Intelligence (AI) and the notion of frame introduced by M. Minsky (1975) in this field of study. Here Frame semantics relates to the notion of frame-based systems of knowledge representations in AI. This is a highly struc- 
tured approach to knowledge representation, which brings together information about particular objects and events and classifies them into a taxonomic hierarchy similar to biological taxonomies.

On the other hand, in case grammar a case frame represents an abstract scene which recognizes the participants of the scene (at least). In the sentences they correlate to the arguments of the predicates. In order to interpret correctly a particular sentence the speaker needs to have mental access to such schematized scenes ${ }^{1}$. One cannot understand completely the meaning of a single word (a lexical sign) without access to all the necessary background knowledge relevant to that word. A common example of a frame, which illustrates the origin of Frame semantics from Fillmore's case frames is the commercial transaction frame. In Table 1 the concept frame is applied to buy with in order to represent the relationships between syntax and semantics.

Table 1. Commercial transaction frame applied to $B U Y$.

\begin{tabular}{|l|l|l|l|l|}
\hline \multicolumn{1}{|c|}{ BUYER } & \multicolumn{1}{|c|}{ buy } & \multicolumn{1}{c|}{ GOODS } & \multicolumn{1}{c|}{ (SELLER) } & \multicolumn{1}{c|}{ (PRICE) } \\
\hline subject & & object & from & for \\
\hline Samantha & bought & a map & from the newsa- \\
gent's & for $€ 10$ \\
\hline Jonas & bought & it & & for $€ 1$ \\
\hline Elizabeth & bought & a slicer & from Stephen & \\
\hline
\end{tabular}

Table 1 shows that the verb buy requires an obligatory BUYER and GOODS and optionally a SELLER, PRICE, setting, particular interpersonal and sociocultural relationships that link the buyer and the seller, and so forth. A certain perspective is also adopted; in the case of buy, the focus is carried by the buyer, not the seller. Hence, frames are based on both learned information and repetitive experiences in life, which store in one's memory the commercial-transaction frame that would be accessed by the word buy in a relevant context.

Verbs from the same semantic field such as sell are expected to have the same meaning slots but in a syntactically different order, which clearly shows the relation to Fillmore's case frames:

Table 2. Commercial transaction frame.

\begin{tabular}{|l|l|l|l|l|l|}
\hline \multicolumn{1}{|c|}{ VERB } & \multicolumn{1}{|c|}{ BUYER } & GOODS & SELLER & MONEY & PLACE \\
\hline buy & subject & object & from & for & at \\
\hline sell & to & & & & \\
\hline cost & $\begin{array}{l}\text { indirect } \\
\text { object }\end{array}$ & subject & & object & at \\
\hline spend & subject & on & & object & at \\
\hline
\end{tabular}

${ }^{1}$ Different terminology, considerably overlapping, is used by cognitive linguists. For instance, instead of frames Lakoff (1987) proposed Idealized cognitive models, cognitive psychologists suggest Mental models, while Fauconnier (1994) deals with Mental spaces. 
Corresponding frames are evoked by other verbs in particular contexts. Verbs of motion, for instance require an obligatory subject and an optional setting pointing out the SOURCE, GOAL, PATH and MANNER of the activity. The corpus of technical texts exhibits the following examples (see Tables 3 and 4$)$ :

Table 3. Actual Motion Frame applied to RUN.

\begin{tabular}{|c|c|c|c|c|c|}
\hline RUNNER & verb & (SOURCE) & (GOAL) & (PATH) & (MANNER) \\
\hline Ions & run & & & around the torus & \\
\hline These lasers & run & & & & $\begin{array}{l}\text { on several } \\
\text { longitudinal } \\
\text { modes }\end{array}$ \\
\hline The plasma & runs & & to the wall & & \\
\hline Currents & run & $\begin{array}{l}\text { from the mag- } \\
\text { netosphere }\end{array}$ & $\begin{array}{l}\text { to the iono- } \\
\text { sphere }\end{array}$ & $\begin{array}{l}\text { along the mag- } \\
\text { netic field lines }\end{array}$ & \\
\hline .. it [oil] & runs & $\begin{array}{l}\text { out of the plug } \\
\text { hole. }\end{array}$ & & & \\
\hline ...the ship & is running & & & & on even keel. \\
\hline ...the shaft & is running & & & & $\begin{array}{l}\text { at normal } \\
\text { speed... }\end{array}$ \\
\hline $\begin{array}{l}\text { The distribu- } \\
\text { tor pump's } \\
\text { drive shaft }\end{array}$ & runs & & & $\begin{array}{l}\text { in bearings in } \\
\text { the pump hous- } \\
\text { ing... }\end{array}$ & \\
\hline Tankers & run & & aground & & \\
\hline
\end{tabular}

Table 4. Actual Motion Frame applied to ENTER.

\begin{tabular}{|l|l|l|l|l|l|}
\hline \multicolumn{1}{|c|}{ ENTERER } & \multicolumn{1}{|c|}{ verb } & \multicolumn{1}{|c|}{ GOAL } & SOURCE & \multicolumn{1}{|c|}{ PATH } & MANNER \\
\hline The DC & enters & the alternator & & $\begin{array}{l}\text { through a set } \\
\text { of carbon } \\
\text { brushes and } \\
\text { slip rings. }\end{array}$ & \\
\hline ...the fluid & entered & $\begin{array}{l}\text { the mouth of } \\
\text { the pipe }\end{array}$ & & & smoothly... \\
\hline $\begin{array}{l}\text { The exhaust } \\
\text { gas }\end{array}$ & may enter & the turbine & $\begin{array}{l}\text { directly from the } \\
\text { engine or from a } \\
\text { constant-pressure } \\
\text { chamber. }\end{array}$ & & \\
\hline steam & enters & & & at the centre of \\
the shaft & \\
\hline
\end{tabular}

The verbs of fictive motion included in the corpus follow the same pattern requiring a subject (a fictive mover), a SOURCE, GOAL and/or PATH and optionally MANNER. 
Table 5. Fictive Motion Frame applied to $R U N$.

\begin{tabular}{|c|c|c|c|c|c|}
\hline $\begin{array}{l}\text { FICTIVE } \\
\text { RUNNER }\end{array}$ & verb & SOURCE & GOAL & PATH & (MANNER) \\
\hline $\begin{array}{l}\text { The fore- } \\
\text { body of the } \\
\text { rudder }\end{array}$ & runs & & $\begin{array}{l}\text { into a rear body } \\
\text { section which is } \\
\text { concave. }\end{array}$ & & \\
\hline $\begin{array}{l}\text { The fire } \\
\text { main }\end{array}$ & runs & & & $\begin{array}{l}\text { the length of } \\
\text { the ship }\end{array}$ & $\begin{array}{l}\text { in the form of } \\
\text { two ring } \\
\text { mains... }\end{array}$ \\
\hline $\begin{array}{l}\text { Cargo han- } \\
\text { dling wires }\end{array}$ & run & from two winches & & & \\
\hline ...pipes & run & $\begin{array}{l}\text { from the distribu- } \\
\text { tion valve (or cock) } \\
\text { chests }\end{array}$ & to the fuel tanks & & \\
\hline $\begin{array}{l}\text { Girder-like } \\
\text { cross- } \\
\text { sections }\end{array}$ & run & & & $\begin{array}{l}\text { through the } \\
\text { engine hous- } \\
\text { ing }\end{array}$ & $\begin{array}{l}\text { in a longitudi- } \\
\text { nal direction }\end{array}$ \\
\hline $\begin{array}{l}\text { This equilib- } \\
\text { rium line }\end{array}$ & $\begin{array}{l}\text { runs } \\
\text { across }\end{array}$ & $\begin{array}{l}\text { from a low speed } \\
\text { line at low pressure } \\
\text { ratio }\end{array}$ & $\begin{array}{l}\text { to a high speed } \\
\text { line at high pres- } \\
\text { sure ratio. }\end{array}$ & [across] & \\
\hline $\begin{array}{ll}\text { Lines } & \text { of } \\
\text { piping } & \end{array}$ & run & & & $\begin{array}{l}\text { through cargo } \\
\text { tanks }\end{array}$ & \\
\hline
\end{tabular}

Research in Frame semantics seeks to find and define the various reasons for creating a conceptual category (sense) related to a given word in each of the different cultural settings in which it is used, or not used. This usage is part of the word's overall meaning. Frame theory makes no difference between referential (denotative) meaning and encyclopedic meaning, as was done in the old componential semantic approach ${ }^{2}$. Knowledge of frames allows people to understand words, while encyclopedic knowledge is necessary for understanding concepts, and this knowledge is complementary in our brains.

Image schemas are a subtype of frames that seem to be fundamental and universal, playing a role across languages. They focus largely on physical relations, motion, and perception. Cognitive linguists argue they are important to the brain for making sense of more complex ideas. The frames ${ }^{3}$ and constructions ${ }^{4}$ (words, syntax, etc.) of a language combine universal schemas in specific ways.

The following image schemas are the most widely used cross-linguistically:

- Trajector-Landmark: this is an asymmetric relationship between two entities, one of which (the trajector) is moveable in most of the cases and is described in reference to the other one (the landmark)

- Container: (literal or metaphorical), i.e. a box, a room, a geometric shape, a cell, a body, a geographic region. The Container has a boundary which sets apart the interior from the exterior.

- Source-Path-Goal (SPG): This schema represents a prototypical motion event, where the moving entity starts at a source and moves via a path to arrive at a goal. It is also used metaphorically (e.g. This theory ran into many complications - this does not refer to literal motion).

Other image schemas include overlap, surrounding, near-far, vertical orientation, etc.

(5) The electrons and ions run into the containment vessel...

\footnotetext{
2 "One should not assign to the semantic structure of the lexicon all the culturally relevant encyclopedic information existing in the culture, but include in the meaning only those components marked by lexical and distribution contrasts" (Nida 1975:137).

${ }^{3}$ In some of the literature, "schema" (also "script") is just a synonym for "frame". In Embodied Construction Grammar, the schema keyword will be used for frames as well as image schemas.

${ }^{4}$ See section 3 of the present paper.
} 
This example evokes Trajector-Landmark, Container, and SPG. The motion of the electrons and ions is being described relative to the vessel. The trajector is associated with the mover role of SPG, which is filled in our scenario with the plasma. The landmark is bound to the container role, i.e. the vessel. Due to the sentence structure the landmark here is the entire container. Because there is motion along a path, we use SPG (see Figure 1):

\section{Source/Path/Goal}

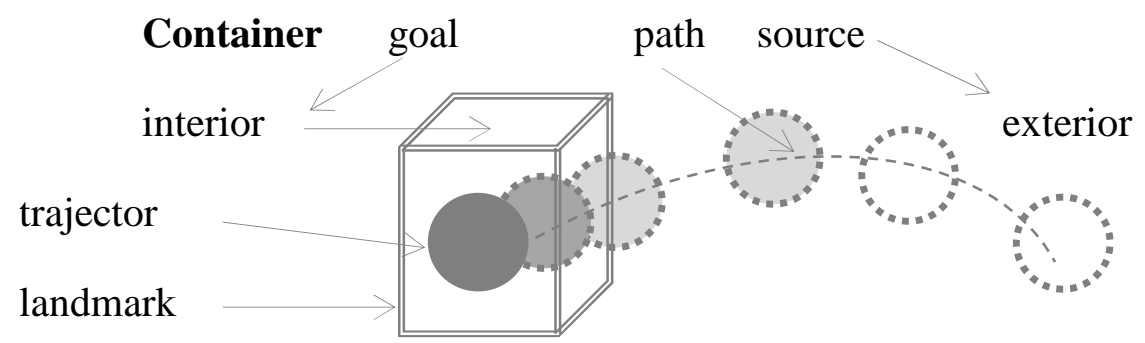

Fig. 1. Source/Path/Goal frame of motion verbs

- The source is where the motion starts (for into and through this is the exterior of the vessel (container); for out of it is the interior of the vessel.

- The goal is where the motion ends (for into this is the interior of the vessel; for out of and through it is the exterior of the vessel).

- The path is where the mover is during the motion (for into and out of it is the opening of the vessel; for through it is the entire interior of the vessel.

Frame semantics is applied to a wide range of subfields of linguistic theorizing such as Language Acquisition, Discourse Analysis, and Typology. Research shows that the central and most successful application seems to be (computational) lexicography. In a frame-based lexicon the frame explains the related senses of a single word and its semantic relations to other words. A frame-based lexicon therefore offers more comprehensive information than the traditional lexicon. An example of computational lexicography is the FrameNet-System (see Boas 2002).

Frames, as used in FrameNet, consist of sets of roles and relations that form part of the meaning of a lexical item. In the analysis of the following examples from the corpus:

(6) However, this is very hard to do, and you run the risk of frequent stalls,

(7) They should not be ignored as, although this would 'play safe' in calculating the main hull strength, it would run the risk that the superstructure itself would not be strong enough to take the loads imposed on it at sea.

the software illustrates the frame of the collocation run the risk. 


About FrameNet - Documentation - FrameNet Data - Related Projects - Bibliography

FrameNet Data

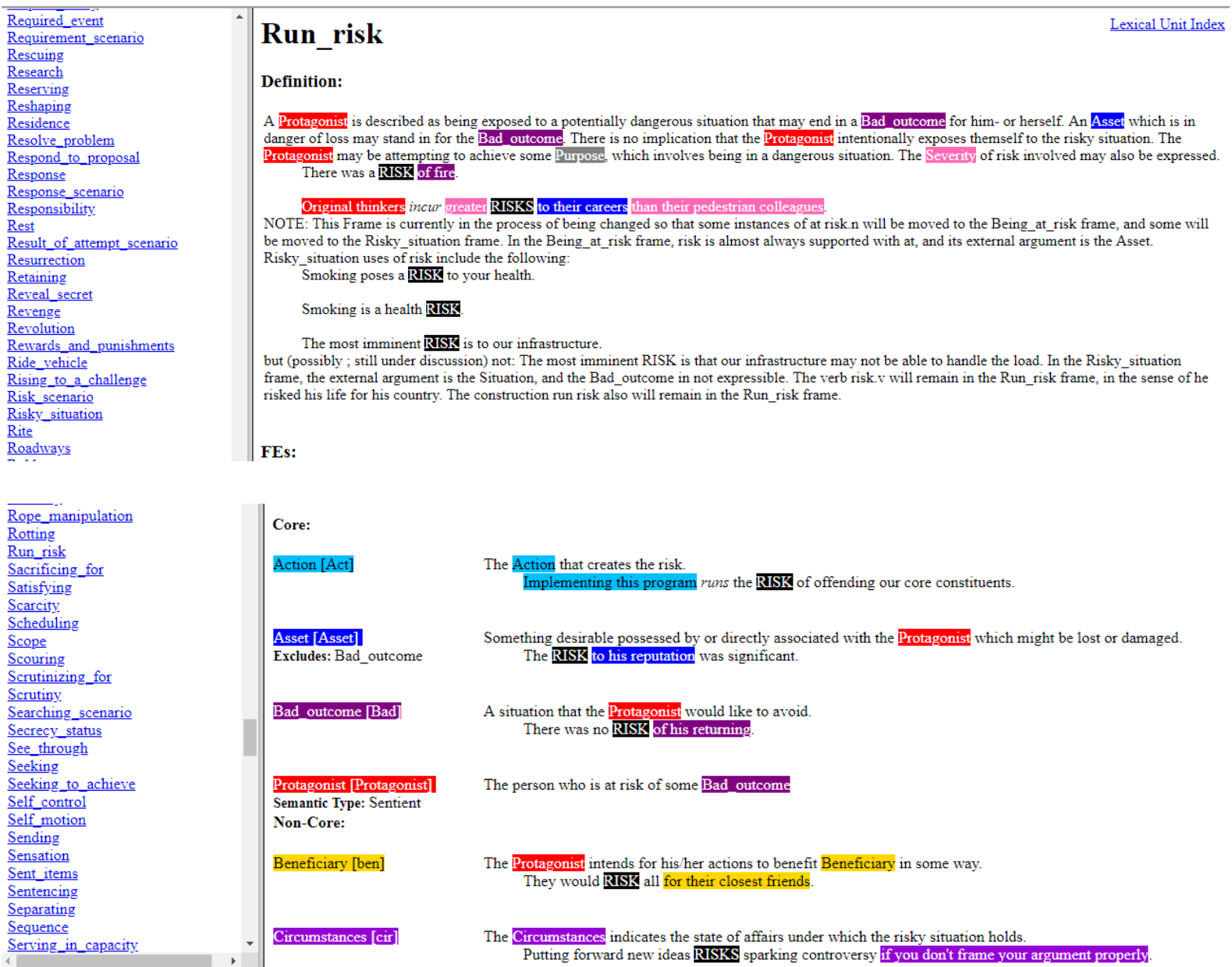

Run the risk requires a number of core roles and relations as Protagonist, Action, Asset, Bad outcome. As for the non-core ones, they are Beneficiary and Circumstances. Although no specialized corpus can be uploaded in the program and it only uses its own data, still it contains sufficient information to outline the frame of the analysed collocation.

\section{Windowing of attention}

The term is used by Leonard Talmy (1993) to refer to placing a portion of a coherent referent situation into the foreground of attention by the explicit mention of that portion, while placing the remainder of that situation into the background of attention by omitting mention of it. The explicitly mentioned information "windows the attention" and sets the event frame. The implicit information in Talmy's words is "gapping". He illustrates his theory with the following examples:

(8) I spent $50 €$ on this book at that store last Friday.

$\longleftrightarrow$ windowed $><$ gapped


(9) I spent $50 €$ on this book at that store last Friday.

windowed gapped

(10) I spent $50 €$ on this book at that store last Friday.

windowed

Talmy suggests three options for windowing in the above example depending on the choice of the speaker regarding the information he/she would like to convey to the listener.

(11) I spent $50 €$ on this book at that store last Friday.

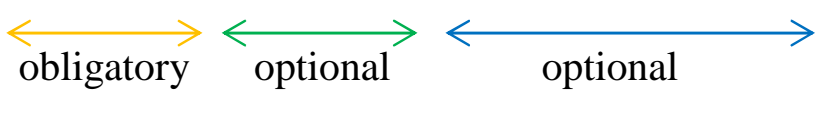

complement complement adjunct

The event frame of the verb spend evokes SELLER, BUYER, GOODS and MONEY. Other types of event frames involve the following elements:

- Path

- Causal chain

- Cycle

- Participant interaction

- Interrelationship

A Path Frame is windowed by an object that is physically in motion in the course of a period of time, therefore it has a beginning and an end, for instance:

(12) Currents run from the magnetosphere to the ionosphere along the magnetic field lines.

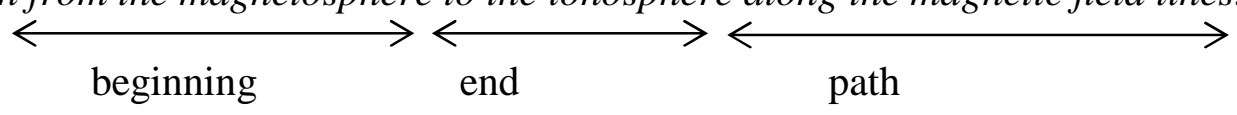

This example windows both the beginning and the end of the running motion together with the path.

Three types of paths can be differentiated according to Talmy (1993):

- Open path: directs one's attentional focus to the beginning of the motion and the end is "gapped", e.g. Three locations on samples from various regions were run...

- Closed path: directs one's attentional focus to the end of the motion and the beginning is "gapped", e.g. This magnetic field... does not allow the plasma to run to the wall.

- Fictive path: directs one's attentional focus along a spatial path, e.g. X be across Y from Z

The Causal Chain Event Frame presents a sequence of sub-events, for instance:

(13) Ti-iProp reduced the thickness of the TiO2 underlayer to $23 \mathrm{~nm}$ by running 700 cycles.

Initiatory agent

body of intention

A Cycle Event Frame is realized through windowing of a phase that is iterated a number of times (see Figure 2): 


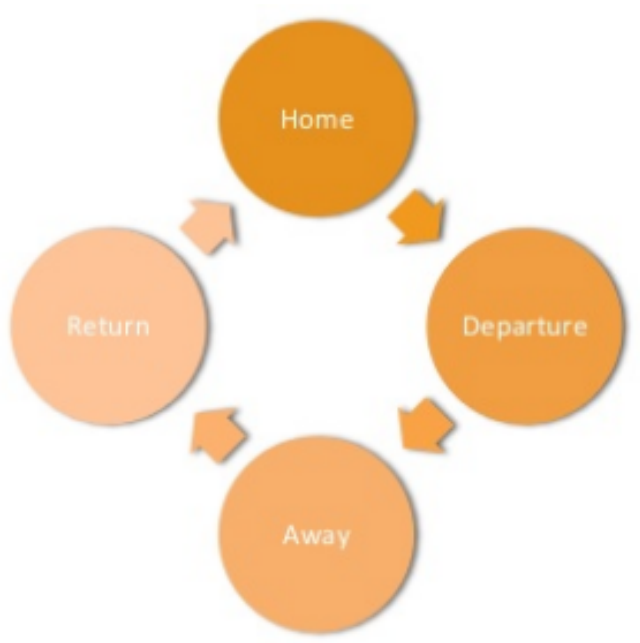

Fig. 2. Cycle Event Frame

(14) Once the electrons have passed the depletion region they move back...

$$
\text { departure phase }
$$

return phase

The above example illustrates phase windowing, designating the departure part of the phase of the moving entity and the return part of the phase to the initial position.

The Participant-Interaction Windowing involves a situation that consists of two stages: (1) a primary circumstance, (2) some participant(s) interacting with that circumstance.

\section{(15) They run away together (energetic neutral atoms) until they tire of one another}

Participant 1

Circumstance

and thus become separated (plasma).

\section{Participant 2}

The Interrelationship Windowing is comprised of elements which are intrinsically relative with respect to each other. The most salient is the Figure-Ground interrelationship (it is accounted for in detail later in the paper), i.e.

(16) The plasma disappeared in a thousandth of a second, running to the walls of the Stellarator.

Figure

\section{Ground}

Figure-ground segregation is indispensible when we try to separate a figure in a picture from the background. The figure is the focal element that stands out from the background. The Figure is the concept that needs a reference object to be defined, and the Ground is the concept that serves as a reference object. In a context these two concepts can be represented by a pair of static or moving objects interrelated in space - expressed by noun phrases in a simple clause. Or the concepts can be events related in time, or by cause, or other type of situation - expressed by the main and subordinate clauses of a complex sentence.

The terms Figure and Ground are adopted from Gestalt psychology. In their linguistic usage, they have a number of specific characteristics. The Figure is more "thing like" and more prominent than the ground. The Figure is seen as being in front of the background and having definite contours when compared to the Ground. The Figure is the moving entity. The non-symmetrical or more abstract ob- 
ject is often perceived as the Ground. The Ground is seen as more "substance like" and extending beyond the contours of the Figure. It is a static reference entity, relative to a reference frame, which serves to characterize the Figure's path, location and orientation.

This triple division of a spatial scene into a Figure, Ground and reference frame allows us to find correspondence between the linguistic Figure/Ground concepts to the psychological figure/ ground concepts. When the Figure and Ground in a linguistic representation are considered only with respect to their relation to each other, apart from any background, then the former object is indeed the psychological figure and the latter object is the psychological ground. Such a double division of a spatial scene is the likeliest conceptualization for a sentence like (19) The plasma runs to the wall. But consideration of a background can be further included for a triple scene division. This is the likeliest conceptualization for a sentence like (20) Ions run around the torus, since here one must consider not only the two principal objects, the ions and the torus, but also the region surrounding the torus, around which the ions move.

Another type of interrelationship is the Factual/ Counterfactual interrelationship.

(17) We have omitted the complicated equations, the incomprehensible big and small numbers and $\sim A$ (Counterfactual)

the sophisticated graphs. Instead, we have inserted some simple graphs and pictures.

\section{$A$ (Factual)}

We will adopt Talmy's symbols for representing the alternatives, using $\boldsymbol{A}$ to stand for the factual alternative and $\sim \boldsymbol{A}$ to designate the corresponding counterfactual one (2000, p. 297). Thus the above example (17) could be considered in terms of the following paraphrase in order to illustrate more clearly the particular interrelationship:

(17a) We have [not inserted] the complicated equations, the incomprehensible big and small numbers and the sophisticated graphs. Instead, we have inserted some simple graphs and pictures.

The paraphrased predication can be interpreted as representing $\boldsymbol{A}$ as more desirable than its counterfactual $\sim \boldsymbol{A}$, i.e. the occurrence of $\mathrm{A}$ and the nonoccurrence of $\sim \boldsymbol{A}$ is the preferable event realization.

Multiple instance of windowing can occur at the same time, each with respect to several concurrent event frames:

(18) (a) Currents run from the magnetosphere to the ionosphere along the magnetic field lines.

Figure
(path event with full windowing featuring Figure, Fact-of-Motion, Source, Goal and Path)

(b) ...the plasma runs to the wall

Figure Goal

(path event with final windowing and initial and medial gapping featuring Figure, Fact-of-Motion and Goal)

(c) These lasers would always run at or below the QNL. Figure

Ground

(interrelationship event/Figure, Ground)

(d) Once the parameters are set, we run the line scan a few times.

Agent Resulting subevent

(initiator agent - causal-chain event, gapping the Ground and the intervening actions and windowing the Initiator/agent and the Resulting subevent; the Resulting subevent is put into an iterative cycle and represents a cycle event frame)

(e) Once the electrons have passed the depletion region they move back...

Factual event (Figure+Fact-of-Motion+Ground) Figure Path (The Ground is gapped)

(factual/path/cycle event with factual event windowing and the counterfactual event being gapped)

(f) If they run at different speeds, in order to calculate the temperature one has first to calculate 
Factual event (Figure+Fact-of-Motion+Manner, Ground and Path gapping)

their velocity relative to the center of mass. (comparison frame/ Factuality event, with Factual event windowing and Counterfactual gapping)

According to Talmy (2000), an 'equational' sentence can be considered as an extension of Figure and Ground from the physical domain. Its very name implies the equivalence of its elements. Actually, it exemplifies the same difference as to a figure versus reference point corresponding to what we saw above for the spatial sentences. This can be illustrated in an inverse pair of sentences like the following:

(21) If all the children are running at exactly the same speed the temperature is zero.

? If all the children are running at exactly the same speed zero is the temperature.

Talmy suggests it is appropriate to interpret the former example as a fixed reference point and the latter as displaced, and inappropriate to treat them vice versa, hence the difference in acceptability between the otherwise equivalent inverse sentences.

This semantic parallel between 'equational' sentences and locative sentences is further elaborated by including in their underlying deep structures the preposition $a t$, hence at the surface it will look as, for example,

(22) ... the temperature is at zero.

There is in fact syntactic evidence for something of this sort in English with the preposition as, at least for copula sentences where the second nominal expresses the role or function of the first.

(23) The SPS now operates as one of the accelerators in the LHC chain.

(24) ...the slave laser will operate as a free running laser.

Figure and Ground properties can involve semantic factors beyond those treated so far - such as perspective point, multipart complexity, incorporation into action or direction, indeterminacy, and multiple embedding - each associated with certain syntactic patterns. However, studying these factors in detail remains outside the scope of this paper.

\section{Construction grammar}

The main motivation behind Construction Grammar is the assumption that grammatical constructions can be meaningful, in part independently of the content words that realize specific instances of the construction.

Research in the field of construction grammar shows that there are a number of different types, each with its own specific characteristics: Kay and Fillmore's (1999) theory of Construction Grammar, Goldberg's Construction Grammar, Radical Construction Grammar (cf. Croft 2005), Embodied Construction Grammar (Bergen, Chang 2002). Due to the limitations of this paper we only focus on Goldberg's Construction Grammar (1995).

Goldberg (1995, p. 24) explores the nature of the relationship between verbs and constructions by posing three questions:

What is the nature of verb meaning?

What is the nature of constructional meaning?

When can a given verb occur in a given construction?

To answer the first question Goldberg argues in favour of the Frame Semantics view of verb meaning (e.g. Fillmore 1977b, 1982), which we discussed in the first section. Goldberg argues that this account of word meaning which claims that the meaning of individual words is understood against the background of a particular conceptual frame (or domain, in Langacker's terms) is necessary, among other reasons, for explaining the distribution of adverbial expressions. Consider the examples in (25).

(25) (a) Lily staggered into the kitchen slowly.

(b) ??Lily bounded into the kitchen slowly.

Goldberg suggests that a frame provides the basis of our understanding of the nature and manner of the motion involved, which explains why slowly can accompany stagger but not bound.

To answer the second question, Goldberg (1995) claims that constructions form a network. Within this network, some constructions share the same meanings. This means that constructions are not asso- 
ciated with unique fixed meanings, but that they interact with other constructions in a rather "fluid network of relationships". It follows from this view that constructions, just like words, will exhibit polysemy, for instance (26).

(26) (a) Mary faxed John a report.

(b) Mary knitted John a hat.

(c) Mary owes George a dollar.

All the instances in (26) are ditransitive constructions. (26a) implies SUCCESSFUL TRANSFER of the report to John, example (26b) only implies INTENDED TRANSFER (it's possible that Mary will suffer a crisis of confidence and John will never see the hat). In (26c), it is unclear whether John will ever receive the money, or indeed whether Mary even intends to repay it. In Goldberg's words, SUCCESSFUL TRANSFER (26a) represents the prototypical sense of the ditransitive construction, while the other examples share only aspects of the prototypical sense (TRANSFER) while differing from it in other respects (the TRANSFER is intended or potential). These examples also show how the construction and the verb itself contribute to the overall meaning of the sentence. While the construction determines what the possible meanings are (TRANSFER, successful or otherwise), the verb determines which of these possible meanings is realised. According to Goldberg, "constructions which correspond to basic sentence types encode as their central senses event types that are basic to human experience". (Goldberg 1995, p. 39). The TRANSFER of an entity from one person to another is a common scene in everyday life, which makes it basic and fundamental to human experience.

To answer the third question and to explain what rules the choice of a particular verb in a particular construction, Goldberg proposes that while verbs are associated with participant roles, constructions have argument roles. In other words, the Frame semantics of a given verb, as we saw in the first section, is associated with frame-specific participants. For example, the verb go might be associated with the participant roles MOVER, SOURCE and GOAL, while the verb play might be associated with the participant roles PLAYER and GAME. These examples exhibit that participant roles are related to rather specific meanings associated with their frame/ domain of experience. Additionally, Goldberg adopts Langacker's (1987) view that a particular verb profiles particular participants within its frame.

(27) (a) Bob robbed Mary (of hope).

(b) *Bob robbed hope (from Mary)

(28) a. Bob stole hope (from Mary).

(b) *Bob stole Mary (of hope)

While rob obligatorily profiles THIEF (Bob) and TARGET (Mary), steal obligatorily profiles THIEF (Bob) and (metaphorical) GOODS (hope). Optionally, either verb may represent a third participant as a peripheral prepositional phrase $(27 \mathrm{a} ; 28 \mathrm{a})$, the sentences become ungrammatical if this optional participant is represented as the direct object (27b; 28b).

The two verbs are related because they are associated with the same set of participant roles, THIEF, TARGET, GOODS. The difference between the two verbs is captured in terms of their profiling properties: $r o b$ profiles TARGET instead of GOODS, steal profiles GOODS instead of TARGET.

Unlike the specific characteristics of participant roles, the argument roles in the sentence-level constructions of Goldberg's model are of a more general semantic kind. This type of approach divides the clause into predicate and arguments. From the point of view of semantic roles, the predicate is usually a single word that can be considered as the central element of the sentence. This word expresses the action, event, property or relation that the clause describes.

The semantics of the predicate determines that it will take a certain number of arguments which are the participants or entities that the predicate requires in order to complete its meaning: a verb like arrive only involves a single participant, while a verb like hit involves two and a verb like send involves three. The term valency is traditionally used to refer to the number and type of arguments that a predicate requires; argument structure is an alternative term for valency. Apart from the obligatory parts of the sentence that are required by the predicate, there are optional parts that provide circumstantial information (expressions of place, manner, time, etc. They are not included in the argument structure of that predicate.

However, the semantic roles approach goes not only study the number of arguments required by a predicate but also looks at the types of arguments required in terms of their semantic properties. For 
example, the verb arrive requires a participant capable of moving in the first place, while the verb send requires a receiver. Another name for semantic roles is thematic roles. Some examples as summarized by Goldberg (1995) are given in (29).

(29) Semantic roles

a. AGENT volitional initiator of action

b. PATIENT undergoes effect of action; change of state

c. THEME moved by action or whose location is described

d. EXPERIENCER sentient and aware of action/state but not in control

e. BENEFICIARY for whose 'benefit' action is performed

f. INSTRUMENT means by which action is performed

g. LOCATION place in which event takes place

h. GOAL entity towards which something moves

i. SOURCE entity from which something moves

Example (30) illustrates a prototypical AGENT and PATIENT.

(30) [We] run [the line scan].

\section{AGENT PATIENT}

The idea of semantic roles stands out in modern linguistics, and both formal and cognitive models use it to address the relationship between grammar and meaning. Semantic roles are central in Langacker's (1987) Cognitive Grammar where the grammatical subject and object participate in a prototypical action chain model. The AGENT is conceived in terms of 'energy source' and PATIENT in terms of 'energy sink'. This model explains active and passive constructions on the basis of marked coding or TR-LM reversal. In this respect, Langacker's model is rather similar to Goldberg's, in that AGENT and PATIENT are not linked directly to individual verbs but to some underlying representation that structures the clause. However, while Langacker focuses on the cognitive model that underlies the clause, Goldberg focuses on the grammatical construction itself that arises from this cognitive model.

Goldberg claims that some constructions are metaphorical extensions of other constructions. For example, she suggests that the resultative construction in (31a) is a metaphorical extension of the caused motion construction in $(31 \mathrm{~b})$.

(31) (a) She was not beautiful, not a woman to make men run mad.

(b) We run the hot plasma into the walls of its containment vessel.

The similarity between these two construction types revolves around the interpretation of the result phrase (the adjective phrase (AP) mad in (31a)) as a type of metaphorical GOAL, parallel to the actual GOAL expressed by the PP (prepositional phrase) in the caused motion construction (into the walls, in (31b)). In other words, the resultative construction denotes a metaphorical movement towards a GOAL or a metaphorical change of location. As Goldberg points out, a further support to this differentiation is the fact that resultatives do not permit GOAL PP phrases. This she explains by the fact that the result (adjective) phrase already expresses the (metaphorical) GOAL, so the expression of an additional GOAL is redundant.

In sum, constructions are related and form a complex network, and any given construction might be linked to a number of other constructions. Although the set of characteristics must be learnt for each group of constructions, novel instances of the construction occur frequently. This reminds of Langacker's notion of entrenchment and emphasizes the usage-based essence of Goldberg's model.

In Goldberg's model, verbs are seen as related to Frame Semantics, thus participant roles are recognised and mapped onto the argument roles, which are determined by the particular construction. From a Construction Grammar perspective, the meaning of linguistic expressions is considered as being identified by the constructions (sentence-level patterns), and not as a sum of the subparts' meaning. 


\section{Conclusion}

This paper presented a number of cognitive linguistic methods and approaches to language studies aiming at the identification of meaning-in-form while focusing on the role of meaning. Cognitive linguistics distinguishes between cognitive semantics and cognitive grammar, the former studying the interrelation between human experience, conceptual system and the semantic structure in language and the latter investigating how cognitive principles are applied in linguistic organization and structuring. Unlike formal approaches to language in which grammatical structure is studied independently of meaning, cognitive grammar and cognitive semantics study the language system and its relations to the conceptual system and embodied experience. Thus, Frame semantics introduces the notion of frames which are schematic representation of experience and serve as background against which the word-meaning is identified and understood. The role of frames and image schemas for the particular meaning recognition and for identifying the obligatory and optional participants in the linguistically expressed events can be traced in different contexts. The corpus of technical texts used in this study showed corresponding event and path frames to those in fiction and media texts. Further, cognitive linguistics uses the concepts of Figure and Ground adopted from Gestalt psychology to analyse linguistic expressions. On the other hand, the constructional approaches to grammar discussed identify grammatical constructions as symbolic units. Moreover, the constructions themselves are 'stored whole' rather than 'built', i.e. language and linguistic expressions, not only in technical texts, can be studied and analysed by analyzing the network of stored constructions rather than studying their subparts. The network of constructions is viewed as ordered and maintained by links established in terms of structure and meaning.

\section{References}

Bergen, B. K., Chang, N. (2005). "Embodied construction grammar in simulation-based language understanding". In Construction Grammars: Cognitive Grounding and Theoretical Extensions, ed. J.-O. Östman and M. Fried. Amsterdam: John Benjamins, 147-190.

Boas, H. (2002). "Bilingual FrameNet Dictionaries for Machine Translation". In Proceedings of the third International Conference on Language Resources and evaluation, Vol. IV., ed. M.G. Rodriguez, C.P.S. Araujo, 1364 1371. University of Las Palmas.

Croft, W. (2002). Radical Construction Grammar: Syntactic Theory in Typological Perspective. Oxford: Oxford University Press.

Evans V., Green M. (2006). Cognitive Linguistics. An Introduction. Edinburgh University Press.

Fillmore, C. (1977a). "The Case for Case Reopened". In Syntax and Semantics 8: Grammatical Relations, ed. P. Cole, 59 - 81. New York: Academic Press.

Fillmore, C. (1977b). "Scenes-and-frames Semantics". In Linguistic Structure Processing, ed. A. Zambolli, 55 - 82. Amsterdam: North Holland Publishing Company.

Fillmore, C. (1977c). "Topics in Lexical Semantics". In Current Issues in LinguisticTheory, ed. R. W. Cole, 76 - 138. Bloomington: Indiana University Press.

Fillmore, C. (2006). Frame semantics. In Cognitive linguistics: Basic readings, ed. D. Geeraerts, 371400. Berlin/New York: Mouton de Gruyter.

Fillmore, C., Baker, C. (2000). Frame Net Web Site.

Fauconnier, G. (1994). Mental Spaces: Aspects of Meaning Construction in Natural Language. New York: Cambridge University Press. p. 240. 
Gawron, J. M. (1983). Lexical Representation and the Semantics of Complementation. Dissertation, University of California, Berkeley.

Goffman, E. (1974). Frame analysis: An easy on the organization of experience. Cambridge, MA: Harvard University Press.

Goldberg, A. (1995). Constructions, A Construction Grammar Approach to Argument Structure. Chicago, University of Chicago Press.

Hamm F., Kamp H., van Lambalgen, M. (2006). "There is no Opposition between Formal and Cognitive Semantics". In Formal Semantics and Cognitive Semantics, Theoretical Linguistics 32.

Kay, P., Fillmore, C. (1999). "Grammatical constructions and linguistic generalizations: the What's X doing Y construction”. Language, 75, 1-34.

Lakoff, G. (1987). "Cognitive models and prototype theory". In Concepts and Conceptual Development: Ecological and Intellectual Factors in Categorization, ed. U. Neisser. New York, Cambridge University Press, 63-100.

Langacker, R. (1987). Foundations of Cognitive Grammar. Vol. 1: Theoretical Prerequisites. Stanford; Stanford University Press.

Langacker, R. (2002). Concept, Image, Symbol: The Cognitive Basis of Grammar, 2nd edn. Berlin: Mouton de Gruyter.

Matsumoto, Yo. (1996). "Subjective motion and English and Japanese verbs". Cognitive Linguistics 7: $183-226$.

Minsky, M. (1975). “A Framework for Representing Knowledge”. In The Psychology of Computer Vision, ed. P. H. Winston, 211 - 277. New York: McGraw-Hill.

Nida, E. A. (1975). Componential analysis of meaning: An introduction to semantic structures. The Hague: Mouton.

Petruck, M. (1986). Body Part Terminology in Hebrew. Dissertation, University of California, Berkeley.

Talmy, L. (1993). "The Windowing of Attention in Language". General \& theoretical papers (337) (Universität Duisburg. Linguistic Agency): L.A.U.D.

Talmy, L. (2000). Toward a cognitive semantics. Vol. I: Concept structuring systems. Cambridge, MA: MIT Press.

van Lambalgen, M., Hamm, F. (2005). The Proper Treatment of Events. Malden, Blackwell.

\section{Online sources}

Ruppenhofer, J., Ellsworth, M., Petruck, M. R. L., Johnson, Ch. R.. (2005). FrameNet: Theory and Practice. Online, available at http://framenet.icsi.berkeley.edu 